\title{
Determinants of initiation, implementation, and discontinuation of amoxicillin by adults with acute cough in primary care
}

This article was published in the following Dove Press journal:

Patient Preference and Adherence

15 March 2017

Number of times this article has been viewed

\author{
David Gillespie,' Daniel \\ Farewell, ${ }^{2}$ Lucy Brookes- \\ Howell,' Christopher C \\ Butler, ${ }^{3}$ Samuel Coenen, ${ }^{4-6}$ \\ Nick A Francis, ${ }^{2}$ Paul Little, ${ }^{7}$ \\ Beth Stuart, ${ }^{7}$ Theo Verheij, ${ }^{8}$ \\ Kerenza Hood'
}

\section{On behalf of the GRACE consortium}

'Centre for Trials Research, College of Biomedical \& Life Sciences, ${ }^{2}$ Division of Population Medicine, School of Medicine, Cardiff University, Cardiff, ${ }^{3}$ Nuffield Department of Primary Health Care Sciences, University of Oxford, Oxford, UK; ${ }^{4}$ Laboratory of Medical Microbiology, Vaccine \& Infectious Disease Institute (VAXINFECTIO), ${ }^{5}$ Centre for General Practice, Department of Primary and Interdisciplinary Care (ELIZA), ${ }^{6}$ Clinical Epidemiology and Medical Statistics, Department of Epidemiology and Social Medicine (ESOC), University of Antwerp, Antwerp, Belgium; ${ }^{7}$ Aldermoor Health Centre, Primary Care and Population Sciences, Faculty of Medicine, University of Southampton, Southampton, UK; ${ }^{8}$ Department of General Practice, Julius Center for Health Sciences and Primary Care, University Medical Center Utrecht, Utrecht, the Netherlands

Correspondence: David Gillespie Centre for Trials Research, College of Biomedical \& Life Sciences, Cardiff University, Heath Park, Cardiff, CFI 4 4YS, Wales, UK

Tel +442920687610

Email gillespied I@cardiff.ac.uk
Aim: To investigate the determinants of adherence to amoxicillin in patients with acute lower respiratory tract infection.

Materials and methods: Three European data sets were used. Adherence data were collected using self-reported diaries. Candidate determinants included factors relating to patient, condition, therapy, health care system/provider, and the study in which the patient participated. Logistic and Cox regression models were used to investigate the determinants of initiation, implementation, and discontinuation of amoxicillin.

Results: Although initiation differed across samples, implementation and discontinuation were similar. Determinants of initiation were days waited before consulting, duration of prescription, and being in a country where a doctor-issued sick certificate is required for being off work for $<7$ days. Implementation was higher for older participants or those with abnormal auscultation. Implementation was lower for those prescribed longer courses of amoxicillin ( $\geq 8$ days). Time from initiation to discontinuation was longer for longer prescriptions and shorter for those from countries where single-handed practices were widespread.

Conclusion: Nonadherence to amoxicillin was largely driven by noninitiation. Differing sets of determinants were found for initiation, implementation, and discontinuation. There is a need to further understand the reasons for these determinants, the impact of poor adherence to antibiotics on outcomes, and to develop interventions to improve antibiotic use when prescribed.

Keywords: adherence, antibiotics, general practice, determinants

\section{Introduction}

Lower respiratory tract infections (LRTIs), characterized by acute cough, account for approximately one-fifth of all consultations in primary care, and the majority of patients who consult are prescribed antibiotics. ${ }^{1,2}$ However, adherence to antibiotics in primary care is often poor. ${ }^{3,4}$ This wastes health care resources, ${ }^{5,6}$ could negatively impact on clinical outcomes, ${ }^{7}$ and could result in infecting bacteria being exposed to sub-optimal levels of treatment; creating an environment that promotes antibiotic resistance. ${ }^{8}$

With concerns growing about the consequences of increasing levels of antimicrobial resistance, ${ }^{9}$ interventions that effectively promote the appropriate use of antibiotics are important. Although most antibiotic stewardship programs have focused on reducing antibiotic use, ${ }^{10,11}$ less attention has been paid to ensuring that antibiotics are appropriately used when prescribed. Interventions for improving adherence are likely to be most effective if they are informed by an understanding of the determinants of sub-optimal adherence. These determinants may operate on multiple levels to impact 
on whether a patient adheres to a prescribed treatment, and therefore large, detailed data sets are required to accurately quantify these influences.

Adherence may be defined as "the process by which patients take their medicine as prescribed". ${ }^{12}$ Traditionally, this has been represented quantitatively as a single variable (eg, percentage of medicine taken as prescribed and a binary taken as prescribed or not). However, recent work in this field encourages the use of the distinct processes involved in taking medicine, namely, initiation, implementation, and discontinuation. ${ }^{13}$ Each individual process may have its own determinants and influences on outcomes. Therefore, different interventions may be required to address each of the adherence processes.

In this paper, we aim to investigate the determinants of initiation, implementation, and discontinuation of amoxicillin by adults consulting with an acute LRTI in European primary care.

\section{Materials and methods}

\section{Studies, patients, settings, and inclusion} criteria for analysis

Data were used from three studies conducted as part of the Genomics to combat Resistance against Antibiotics in Community-acquired LRTI in Europe (GRACE) Network of Excellence research program. ${ }^{14}$ All three studies recruited adult patients aged $\geq 18$ years consulting with an acute LRTI/cough in primary care and are described in detail elsewhere. In brief, Study 1 was a prospective cohort study conducted in 13 European countries between 2006 and $2007 ;^{1}$ Study 2 was an observational study on the etiology, diagnosis, and prognosis of LRTI conducted in 12 European countries between 2007 and 2010; ${ }^{15}$ and Study 3 was a placebo-controlled trial of amoxicillin nested within Study $2 .{ }^{16}$ Following an initial consultation with a clinician, participants in all three studies were given a diary that recorded symptoms, medication use, and health care contacts. Participants were asked to complete their diary for 28 days. All three studies collected data using similar case report forms (CRFs) and patient diaries. Study participants were included in analysis if they were prescribed amoxicillin for immediate use at their initial consultation (defined as being prescribed amoxicillin and not advised to delay, as recorded on the CRF) and it was possible to ascertain adherence measures using self-reported diary data. The present study focuses on the use of amoxicillin only, as this is the recommended first-line antibiotic for LRTI in the European Union. ${ }^{17}$ In Studies 1 and 2, participants who were prescribed antibiotics other than amoxicillin were excluded. In Study 3 (the trial), amoxicillin was the only antibiotic prescribed.

\section{Definition of adherence elements}

\section{Initiation}

Participants were defined as having initiated their amoxicillin if they indicated in their diary that they took amoxicillin at least once during the 28 day follow-up period.

\section{Implementation}

In participants who initiated their amoxicillin, implementation describes the extent to which the prescription was taken as prescribed among those who initiated their amoxicillin. For the purpose of this paper, it is defined as the proportion of amoxicillin reportedly taken during the prescribed period. For example, if a participant was prescribed amoxicillin for 5 days and only reported taking it for 4 days during the first 5 days of the follow-up period, their implementation score would be 0.8 (ie, they initiated their amoxicillin course and took $80 \%$ of it during the prescribing period).

\section{Discontinuation}

Participants were defined as having discontinued their amoxicillin prescription if they initiated their prescription and subsequently reported a full week of not taking their medicine. A gap of 1 week was deemed appropriate in distinguishing between patients who stopped and restarted their medicine and those who were prescribed a new course of amoxicillin. The first day of that 1-week gap was defined as the day they discontinued, and the time to discontinuation was calculated as the difference in days between the day of discontinuation and the day of initiation. For example, if a participant was prescribed a 7-day course of amoxicillin, initiated their amoxicillin on day 3, and days 10-17 were the first full week where no amoxicillin was reportedly taken, they would be defined as having discontinued on day 10 , and their time from initiation to discontinuation would be 7 days.

\section{Candidate determinants}

Determinants related to the patient, illness, prescription, and health care setting were investigated. A full description of the candidate determinants is given in the online supple$\underline{\text { mentary materials. }}$

\section{Statistical analysis}

Descriptive statistics were reported as numbers and percentages, means and standard deviations (SDs), or medians and interquartile ranges (IQRs), as appropriate. 
Findings in all descriptive tables are presented both overall and separately for each study.

A three-level logistic regression model was fitted to investigate the determinants of initiation, with participants nested within clinicians nested within countries.

To investigate the determinants of implementation, a multilevel logistic regression model was fitted to participants who had initiated amoxicillin. The model allowed for clustering at four levels, specifically, days nested within participants nested within clinicians nested within countries. This approach, therefore, modeled implementation as the probability of correctly implementing on a given day.

A Cox proportional hazards model ${ }^{18}$ was fitted to investigate the determinants of time from initiation to discontinuation. The standard errors from this model were corrected for the clustering of participants within clinicians.

Throughout, results are presented in terms of odds ratios (ORs), hazard ratios (HRs), and associated 95\% confidence intervals (CIs), as appropriate. Variables were entered into a univariable model and retained if they were significant at the $P<0.1$ level. Variables in the multivariable model that were not significant at the $P<0.05$ level were removed sequentially, from largest to smallest $P$-value, until a final multivariable model was attained. The study from which a participant provided data was used in all models (both univariable and multivariable) to ensure that any association was not confounded by the characteristics of participants from different studies.

For initiation and implementation, the clinician and country-level intracluster correlation coefficients (ICCs) were calculated to demonstrate the proportion of variation in initiation/implementation that was attributable to differences between clinicians and countries. Some clinicians participated in more than one of the three studies, and where this was the case their identifier was linked across studies.

Data management and descriptive statistics were conducted using Statistical Package for the Social Sciences, version 20 (IBM Corporation, Armonk, NY, USA). ${ }^{19}$ All other analyses used Stata version $13 .{ }^{20}$

\section{Ethical approval}

The original studies were approved by ethics committees in all participating countries. The work carried out in this paper remains sufficiently within the remit of those original approvals.

\section{Results \\ Descriptive statistics}

Number of participants, clinicians, and primary care networks

In total, data were available for 1,346 participants prescribed amoxicillin for immediate use and for whom self-reported follow-up diary data were available (Study 3, the placebocontrolled trial, $\mathrm{n}=848$; Study 1 , the prospective observational study, $n=306$; and Study 2, the observational study within which the trial was nested, $n=192$ ).

Overall, participants were recruited by 322 clinicians who were based in 15 different countries across Europe (Figure 1).

\section{Participant characteristics}

Participants were aged between 18 and 88 years (median 51, IQR: 38-62). Although the age distributions in Studies 1 and 3 were similar, those recruited into Study 2 tended to be slightly

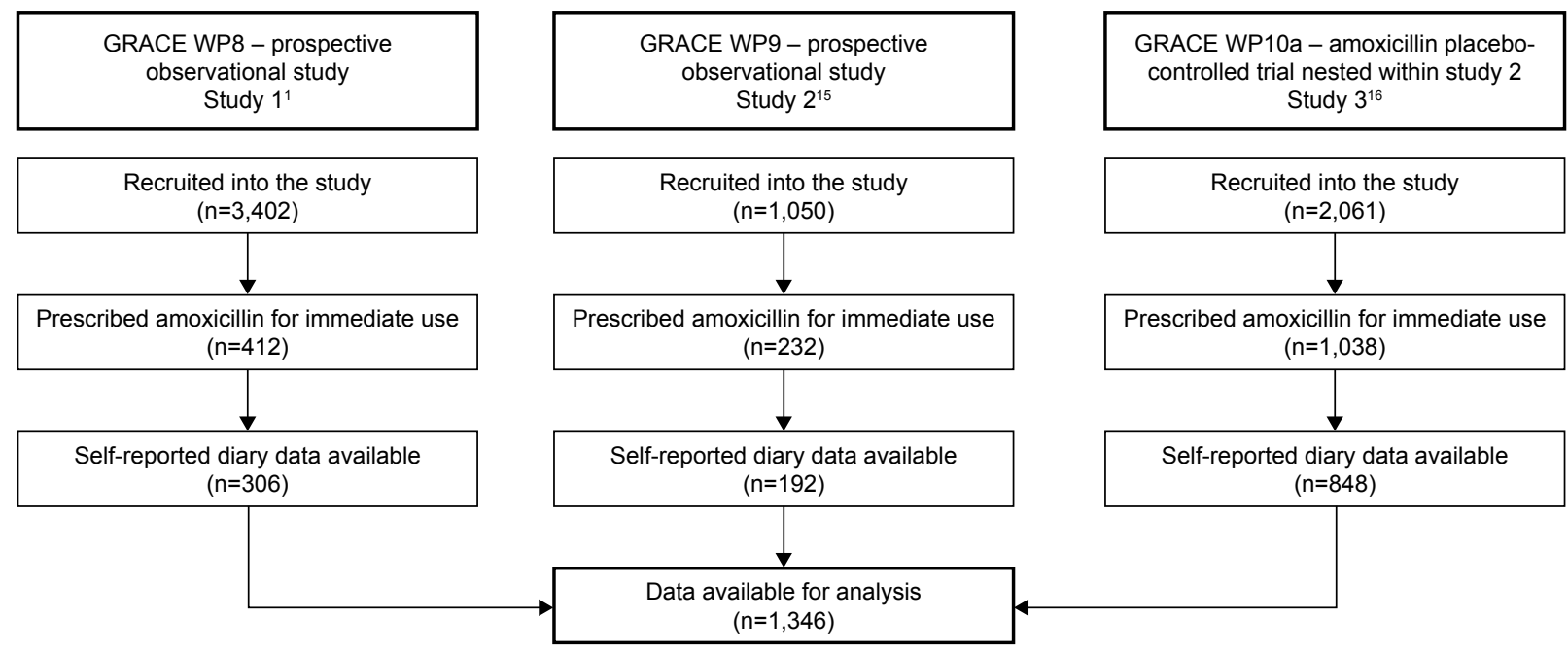

Figure I Study flow diagram.

Abbreviations: GRACE, Genomics to combat Resistance against Antibiotics in Community-acquired LRTI in Europe; LRTI, lower respiratory tract infection. 
older (median 58, IQR: 45-65). Overall, 540 participants were men (40.1\%) and 372 participants had at least one of the listed co-morbidities $(27.7 \%)$. Study 2 contained a higher percentage of participants with co-morbidities (36.5\%; Table 1).

\section{Illness characteristics}

Other than cough, which was part of the inclusion criteria for all three studies, the five most frequently reported symptoms were phlegm (81.3\%), feeling generally unwell (79.8\%), interference with normal activities (69.6\%), disturbed sleep (64.5\%), and shortness of breath (59.0\%). Fever and headache were most frequently reported by participants in Study 1 and coryza by participants in Study 3. Phlegm, shortness of breath, wheeze, disturbed sleep, feeling generally unwell, and diarrhea were the symptoms most frequently reported by participants in Study 2 (Table 1).

Overall, the median clinician-rated symptom severity score at recruitment was 36 (IQR: 25-46), with participants from Study 2 reporting the highest average symptom severity ( median =38, IQR: 26-48) and those from Study 3 the lowest ( median =35, IQR: 25-46). Abnormal findings on auscultation examination were found in 652 participants $(48.5 \%)$, with participants in Study 3 least likely to have abnormal findings (34.3\%). Discolored phlegm was reported by 680 participants (53.2\%; Table 1).

\section{Prescription characteristics}

Although participants in Study 3 were prescribed a fixed dose, frequency, and duration of amoxicillin, it was not fixed for participants in the other two studies. For these participants, the most frequently prescribed dose was $500 \mathrm{mg}$ (218, or $44.2 \%$ of all participants were prescribed this dose), with 393 instructed to take their medication three or more times a day (79.2\%), and 339 prescribed a 6- or 7-day course $(68.3 \%)$. Participants in Study 1 were more likely to be prescribed higher doses to be taken less frequently and for a shorter duration, than those in Study 2 (Table 2).

\section{Healthcare setting characteristics}

Of the 15 countries included, single-handed practices were common in six (40.0\%), campaigns around antibiotic use had recently been conducted in seven (46.7\%), patients were required to pay to see a general practitioner at the point of delivery of care in seven $(46.7 \%)$, and a doctor-issued sick certificate was required for certifying people off work

Table I Participant and illness characteristics by study

\begin{tabular}{|c|c|c|c|c|}
\hline Participant/illness characteristics & Study I $(n=306)$ & Study $2(n=192)$ & Study $3(n=848)$ & Overall $(n=I, 346)$ \\
\hline $\mathrm{Age}^{\mathrm{a}}$ & $49(37-62)$ & $58(45-65)$ & $50(37-6 I)$ & $51(38-62)$ \\
\hline Male $^{\mathrm{b}}$ & $124(40.5)$ & $75(39.1)$ & $34 I(40.2)$ & $540(40.1)$ \\
\hline Female $^{b}$ & $182(59.5)$ & 117 (60.9) & $507(59.8)$ & $806(59.9)$ \\
\hline At least one co-morbidity ${ }^{\mathrm{b}}$ & $77(25.2)$ & $70(36.5)$ & $225(26.6)$ & $372(27.7)$ \\
\hline Clinician-rated symptom severity ${ }^{\mathrm{a}}$ & $36(26-48)$ & $38(26-48)$ & $35(25-46)$ & $36(25-46)$ \\
\hline Phlegm ${ }^{b}$ & $255(83.6)$ & $173(90.1)$ & $665(78.5)$ & $\mathrm{I}, 093(8 \mathrm{I} .3)$ \\
\hline Shortness of breath ${ }^{b}$ & $198(64.7)$ & $143(74.5)$ & $452(53.4)$ & $793(59.0)$ \\
\hline Wheeze ${ }^{b}$ & $175(57.2)$ & $125(65.1)$ & $344(40.6)$ & $644(47.9)$ \\
\hline Coryza $^{b}$ & $204(66.9)$ & $134(69.8)$ & $635(75.0)$ & $973(72.4)$ \\
\hline Fever $^{b}$ & $183(59.8)$ & $79(4 I . I)$ & $290(34.3)$ & $552(4 I . I)$ \\
\hline Chest pain ${ }^{b}$ & $157(5 \mid .3)$ & $100(52.1)$ & $372(44.0)$ & $629(46.8)$ \\
\hline Muscle aching ${ }^{\mathrm{b}}$ & $179(58.5)$ & $108(56.2)$ & $421(49.7)$ & $708(52.6)$ \\
\hline Headache $^{\mathrm{b}}$ & $199(65.0)$ & $104(54.2)$ & $467(55.1)$ & $770(57.2)$ \\
\hline Disturbed sleep ${ }^{b}$ & $213(69.8)$ & I 45 (75.9) & $508(60.0)$ & $866(64.5)$ \\
\hline Feeling generally unwell ${ }^{b}$ & $269(88.2)$ & $174(90.6)$ & $629(74.3)$ & $\mathrm{I}, 072(79.8)$ \\
\hline Interference with normal activities ${ }^{b}$ & $242(79.3)$ & $143(74.5)$ & $551(65.1)$ & $936(69.6)$ \\
\hline Confusion/disorientation ${ }^{\mathrm{b}}$ & $23(7.5)$ & II (5.7) & $23(2.7)$ & $57(4.2)$ \\
\hline Diarrheab $^{\mathrm{b}}$ & $23(7.5)$ & $19(9.9)$ & $53(6.3)$ & $95(7.1)$ \\
\hline Abnormal auscultation finding $g^{b, c}$ & $220(71.9)$ & $142(74.3)$ & $290(34.3)$ & $652(48.5)$ \\
\hline No phlegm ${ }^{\mathrm{b}, \mathrm{d}}$ & $50(16.5)$ & $17(9.1)$ & $133(16.9)$ & $200(15.6)$ \\
\hline Normal colored phlegm b,d & 7I (23.4) & $60(32.1)$ & $268(34.0)$ & $399(31.2)$ \\
\hline Discolored phlegm ${ }^{\mathrm{b}, \mathrm{d}}$ & $182(60.1)$ & $110(58.8)$ & $388(49.2)$ & $680(53.2)$ \\
\hline Waited 7 days or fewer prior to consulting & $212(70.4)$ & $123(65.4)$ & $524(62.7)$ & $859(64.8)$ \\
\hline Waited 8-14 days prior to consulting ${ }^{\mathrm{b}}$ & $68(22.6)$ & $43(22.9)$ & $192(23.0)$ & $303(22.9)$ \\
\hline Waited 15 days or more prior to consulting ${ }^{\mathrm{b}}$ & $21(7.0)$ & $22(11.7)$ & $120(14.4)$ & $163(12.3)$ \\
\hline
\end{tabular}

Notes: a Median (IQR). ${ }^{b} n$ (\%). 'At least one of the following: diminished vesicular breathing, wheeze, crackles, or rhonchi. ${ }^{d}$ Normal colored phlegm $=$ clear or white, discolored phlegm = yellow, green, or bloodstained. Study I: prospective cohort study conducted in I3 European countries between 2006 and 2007.' Study 2: observational study on the etiology, diagnosis, and prognosis of LRTI conducted in 12 European countries between 2007 and $2010 .{ }^{15}$ Study 3: placebo-controlled trial of amoxicillin nested within Study $2 .{ }^{16}$ Abbreviations: IQR, interquartile range; LRTI, lower respiratory tract infection. 
Table 2 Amoxicillin prescription characteristics by study

\begin{tabular}{|c|c|c|c|c|}
\hline $\begin{array}{l}\text { Prescription } \\
\text { characteristic }\end{array}$ & $\begin{array}{l}\text { Study I } \\
(n=306)\end{array}$ & $\begin{array}{l}\text { Study } 2 \\
(n=192)\end{array}$ & $\begin{array}{l}\text { Study } 3 \\
(n=848)\end{array}$ & $\begin{array}{l}\text { Overall } \\
(n=1,346)\end{array}$ \\
\hline \multicolumn{5}{|l|}{ Dose (mg) } \\
\hline$<500$ & $23(12.3)$ & $52(17.0)$ & $0(0.0)$ & $75(5.6)$ \\
\hline 500 & $99(52.9)$ & $119(38.9)$ & $0(0.0)$ & $218(16.3)$ \\
\hline$\geq 500$ to $<1,000$ & $8(4.3)$ & $34(11.1)$ & $0(0.0)$ & $42(3.1)$ \\
\hline \multicolumn{5}{|l|}{ (not inclusive) } \\
\hline$\geq 1,000$ & $57(30.5)$ & IOI (33.0) & $848(100.0)$ & $\mathrm{I}, 006(75.0)$ \\
\hline \multicolumn{5}{|c|}{ Frequency (times per day) } \\
\hline Twice & $13(6.8)$ & $90(29.4)$ & $0(0.0)$ & $103(7.7)$ \\
\hline More than twice & $177(93.2)$ & $216(70.6)$ & $848(100.0)$ & $\mathrm{I}, 24 \mathrm{I}(92.3)$ \\
\hline \multicolumn{5}{|l|}{ Duration (days) } \\
\hline$\leq 5$ & $14(7.3)$ & $59(19.3)$ & $0(0.0)$ & $73(5.4)$ \\
\hline 6 or 7 & $144(75.4)$ & $195(63.9)$ & $848(100.0)$ & $\mathrm{I}, 187(88.3)$ \\
\hline$\geq 8$ & $33(17.3)$ & $51(16.7)$ & $0(0.0)$ & $84(6.2)$ \\
\hline
\end{tabular}

Notes: Data presented as n (\%). Study I: prospective cohort study conducted in 13 European countries between 2006 and 2007.' Study 2: observational study on the etiology, diagnosis, and prognosis of lower respiratory tract infection conducted in 12 European countries between 2007 and $2010 .^{15}$ Study 3: placebo-controlled trial of amoxicillin nested within Study $2 .^{16}$

for $<7$ days in three $(20.0 \%)$. Amoxicillin was the first-line choice of antibiotic in the national guidelines of six of the countries $(40.0 \%)$, and antibiotic prescribing rates ranged from 11.2 defined daily doses per 1,000 inhabitants/day (the Netherlands) to 28.6 defined daily doses per 1,000 inhabitants/day (France), with six countries categorized as low prescribers (the Netherlands, Sweden, Germany, Slovenia, Norway, and Hungary), five as moderate (England, Wales, Finland, Spain, and Poland), and four as high prescribers (Slovakia, Belgium, Italy, and France) (Table 3).

\section{Analysis}

\section{Initiation}

While overall, a high proportion of participants initiated their amoxicillin (1,057 or $78.5 \%$ of participants), this was largely driven by the almost-complete initiation of amoxicillin seen in Study 3 (97.6\%). Initiation in participants from Study 1 and Study 2 was considerably lower $(51.0 \%$ and $38.0 \%$, respectively). When initiation occurred, it was mostly on the day of prescription ( $91.5 \%$ of participants who initiated did so on day 1).

Compared to those who had waited $\leq 7$ days, participants who had waited $\geq 15$ days prior to consulting had higher odds of initiating their amoxicillin (OR $=2.77,95 \%$ CI: 1.35-5.67). There was some evidence that the duration of the prescription was also associated with amoxicillin initiation. Participants who were prescribed amoxicillin for $\geq 8$ days had higher odds of initiating their amoxicillin than those prescribed for $\leq 5$ days, although this was not statistically significant at the $5 \%$ level $(\mathrm{OR}=2.29,95 \% \mathrm{CI}$ : 0.97-5.42). Participants in countries where a sick certificate was required for taking $<7$ days off work had higher odds of initiating their amoxicillin ( $\mathrm{OR}=2.15,95 \% \mathrm{CI}$ : 1.27-3.64) (Table 4).

The ICC from the final multivariable model indicated that $17 \%$ of the total variation in initiation was attributable to differences between clinicians. The country-level ICC was negligible.

Table 3 Health care setting characteristics

\begin{tabular}{|c|c|c|c|c|c|c|}
\hline Country & $\begin{array}{l}\text { Widespread } \\
\text { availability of } \\
\text { single-handed } \\
\text { practices }^{\mathbf{a}}\end{array}$ & $\begin{array}{l}\text { Recent public } \\
\text { campaigns } \\
\text { around } \\
\text { antibiotic use }{ }^{\mathrm{a}} \\
\end{array}$ & $\begin{array}{l}\text { Payment } \\
\text { required to } \\
\text { see general } \\
\text { practitioner }^{\mathrm{a}}\end{array}$ & $\begin{array}{l}\text { Sick certification } \\
\text { required for less } \\
\text { than } 7 \text { days off } \\
\text { work }^{\mathrm{a}}\end{array}$ & $\begin{array}{l}\text { Amoxicillin first- } \\
\text { line choice for a } \\
\text { respiratory infection } \\
\text { in primary care }\end{array}$ & $\begin{array}{l}\text { Antibiotic } \\
\text { prescribing } \\
\text { rate }^{\text {b }}\end{array}$ \\
\hline Belgium & $\checkmark$ & $\checkmark$ & $\checkmark$ & $\checkmark$ & $\checkmark$ & $27.1(25.2-28.2)$ \\
\hline England & & $\checkmark$ & & & $\checkmark$ & $17.4(16.5-18.7)$ \\
\hline Finland & & & $\checkmark$ & & & I8.I (17.8-18.5) \\
\hline France & $\checkmark$ & & $\checkmark$ & & $\checkmark$ & $28.6(28 . I-29.6)$ \\
\hline Germany & $\checkmark$ & & & & $\checkmark$ & $14.6(14.5-14.9)$ \\
\hline Hungary & & & $\checkmark$ & & & $15.6(15.2-16.0)$ \\
\hline Italy & $\checkmark$ & & & & & $28.1(27.6-28.7)$ \\
\hline the Netherlands & $\checkmark$ & $\checkmark$ & $\checkmark$ & & & $11.2(11.1-1 \mid .4)$ \\
\hline Norway & & & $\checkmark$ & & & $15.5(15.2-15.8)$ \\
\hline Poland & & $\checkmark$ & & $\checkmark$ & & $21.9(20.8-23.6)$ \\
\hline Slovakia & $\checkmark$ & $\checkmark$ & & & & $23.9(23.2-24.8)$ \\
\hline Slovenia & & & & & $\checkmark$ & $14.9(14.3-15.9)$ \\
\hline Spain & & $\checkmark$ & & $\checkmark$ & & $19.9(19.7-20.3)$ \\
\hline Sweden & & $\checkmark$ & $\checkmark$ & & & $14.6(14.1-15.5)$ \\
\hline Wales & & & & & $\checkmark$ & $17.4(16.5-18.7)$ \\
\hline
\end{tabular}

Notes: ${ }^{a}$ Obtained from interview data as part of the GRACE project. ${ }^{14}$ b Obtained from the Antimicrobial consumption interactive database (ESAC-Net), ${ }^{30}$ and defined as the defined daily dose per 1,000 inhabitants per day. Rate averaged across years 2007-2010 (min and max values in brackets). United Kingdom rates used for England and Wales.

Abbreviations: GRACE, Genomics to combat Resistance against Antibiotics in Community-acquired LRTI in Europe; LRTI, lower respiratory tract infection; max, maximum; min, minimum. 
Table 4 Three-level multivariable logistic regression model investigating the determinants of the initiation of amoxicillin

\begin{tabular}{|c|c|c|c|c|}
\hline \multirow[t]{2}{*}{ Variables $^{\mathrm{a}}$} & \multirow{2}{*}{$\begin{array}{l}\text { Odds } \\
\text { ratio }\end{array}$} & \multicolumn{2}{|l|}{$95 \% \mathrm{Cl}$} & \multirow[t]{2}{*}{$P$-value } \\
\hline & & Lower & Upper & \\
\hline Waited $\leq 7$ days prior to consulting & \multicolumn{4}{|c|}{ Reference category } \\
\hline Waited 8-14 days prior to consulting & 1.47 & 0.92 & 2.34 & 0.010 \\
\hline Waited I5+ days prior to consulting & 2.77 & 1.35 & 5.67 & \\
\hline Prescribed amoxicillin for $\leq 5$ days & \multicolumn{4}{|c|}{ Reference category } \\
\hline Prescribed amoxicillin for 6 or 7 days & 0.84 & 0.44 & 1.62 & 0.013 \\
\hline Prescribed amoxicillin for $8 \geq$ days & 2.29 & 0.97 & 5.42 & \\
\hline $\begin{array}{l}\text { Sick certification required for } \\
\text { missing }<7 \text { days of work }\end{array}$ & 2.15 & 1.27 & 3.64 & 0.004 \\
\hline Participant from Study I & \multicolumn{4}{|c|}{ Reference category } \\
\hline Participant from Study 2 & 0.46 & 0.28 & 0.75 & $<0.001$ \\
\hline Participant from Study 3 & 56.04 & 27.54 & 114.03 & \\
\hline
\end{tabular}

Notes: ${ }^{\text {TT }}$ The model is based on I,323 participants, nested within 330 clinicians, nested within 15 countries. The intracluster correlation coefficients from the final model were: clinician: 0.17 ; country: 0.00 . Study I: prospective cohort study conducted in 13 European countries between 2006 and 2007.' Study 2: observational study on the etiology, diagnosis, and prognosis of LRTI conducted in 12 European countries between 2007 and 2010. ${ }^{15}$ Study 3: placebo-controlled trial of amoxicillin nested within Study 2. Abbreviations: $\mathrm{Cl}$, confidence interval; LRTI, lower respiratory tract infection.

\section{Implementation}

In participants who initiated amoxicillin, implementation levels were high and highly skewed across all three studies. Full implementation was achieved by 827 participants overall (78.3\%), with full implementation across studies ranging from $70.8 \%$ of participants in Study $2(51 / 72)$ to $80.0 \%$ in Study 3 (662/828) (Figure 2).

The odds of implementing amoxicillin on a given day were higher among older participants (OR for a decade increase $=1.21,95 \% \mathrm{CI}: 1.03-1.41$ ), and there was some evidence that it was higher for participants with abnormal auscultation findings at their index consultation, although the $95 \% \mathrm{CI}$ included 1 (OR $=1.71,95 \% \mathrm{CI}: 1.00-2.91$ ). The odds were lower for participants prescribed courses of amoxicillin lasting $\geq 8$ days (OR compared to courses lasting up to 5 days $=0.07,95 \%$ CI: 0.01-0.42) (Table 5).

Sixty-two percent of the total variation in whether amoxicillin was taken on a given day was attributable to differences between participants. The clinician and countrylevel ICCs were both 0.04 .

\section{Discontinuation}

The median time from initiation to discontinuation of amoxicillin was 7 days across all three studies (overall IQR: 7-8 days).

Longer courses were associated with a longer time to discontinuation (HR for 6-7 days compared with $\leq 5$ days $=0.30,95 \%$ CI: $0.17-0.55$, HR for $\geq 8$ days compared with $\leq 5$ days $=0.19,95 \%$ CI: $0.10-0.36$ ). Participants from countries where single-handed practices were widespread were associated with a shorter time until discontinuation (HR $=1.15,95 \% \mathrm{CI}: 1.03-1.28)$. The findings persisted when the standard errors were corrected for clustering of participants within countries.

\section{Differences across studies}

As indicated by the forest plots presented in the online supplementary materials, there was insufficient evidence to suggest that the determinants found in the models for initiation, implementation, and discontinuation differed within the individual studies.

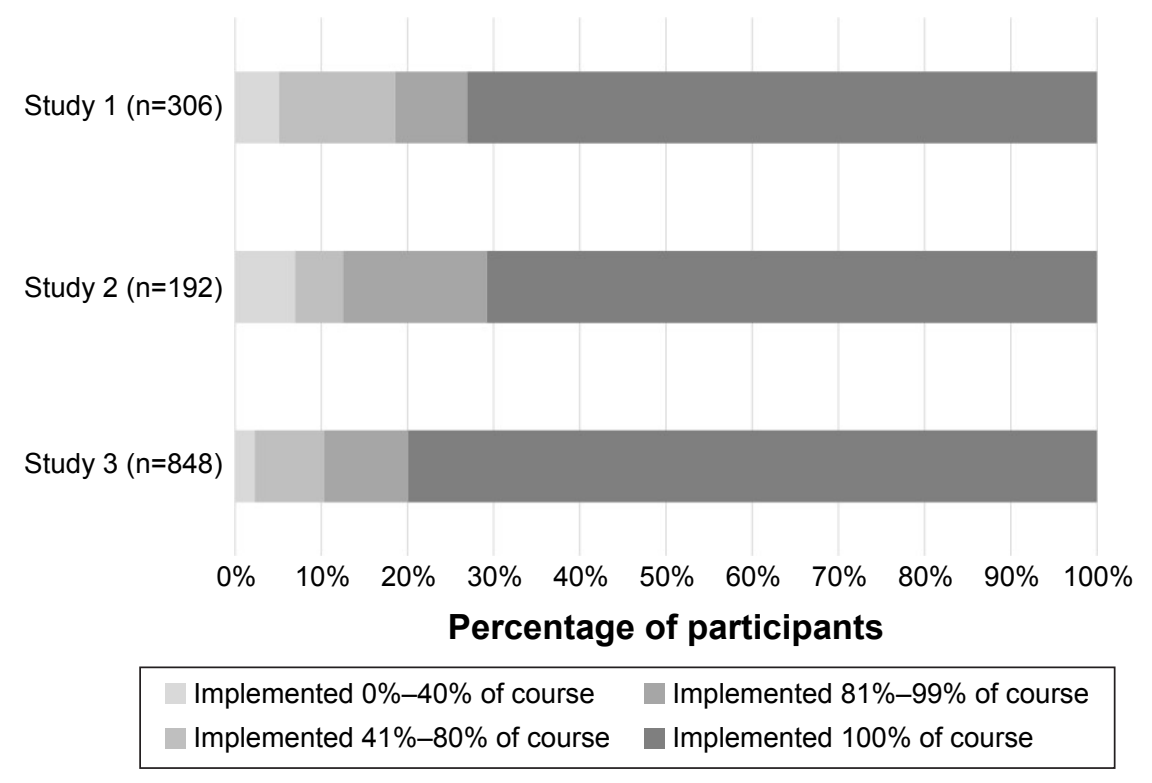

Figure 2 Implementation of amoxicillin by study.

Notes: Study I: prospective cohort study conducted in 13 European countries between 2006 and 2007.' Study 2: observational study on the etiology, diagnosis, and prognosis of lower respiratory tract infection conducted in 12 European countries between 2007 and $2010 .{ }^{15}$ Study 3: placebo-controlled trial of amoxicillin nested within Study $2 .{ }^{16}$ 
Table 5 Four-level logistic regression model investigating the determinants of the implementation of amoxicillin

\begin{tabular}{|c|c|c|c|c|}
\hline \multirow[t]{2}{*}{ Variables $^{\mathbf{a}}$} & \multirow{2}{*}{$\begin{array}{l}\text { Odds } \\
\text { ratio }\end{array}$} & \multicolumn{2}{|l|}{$95 \% \mathrm{Cl}$} & \multirow[t]{2}{*}{$P$-value } \\
\hline & & Lower & Upper & \\
\hline Age (per decade increase) & 1.21 & 1.03 & 1.41 & 0.019 \\
\hline Auscultation abnormality ${ }^{\mathrm{b}}$ & I.7I & 1.00 & 2.91 & 0.050 \\
\hline Prescribed amoxicillin for $\leq 5$ days & \multicolumn{4}{|c|}{ Reference category } \\
\hline Prescribed amoxicillin for 6 or 7 days & 1.18 & 0.22 & 6.25 & $<0.001$ \\
\hline Prescribed amoxicillin for $\geq 8$ days & 0.07 & 0.01 & 0.42 & \\
\hline Participant from Study I & \multicolumn{4}{|c|}{ Reference category } \\
\hline Participant from Study 2 & 1.23 & 0.42 & 3.64 & 0.909 \\
\hline Participant from Study 3 & 1.18 & 0.48 & 2.88 & \\
\hline
\end{tabular}

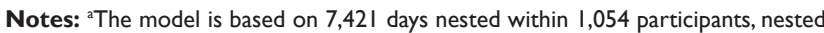
within 281 clinicians, nested within 15 countries. The intracluster correlation coefficients from the final model were: participant: 0.62 ; clinician: 0.04 ; country 0.04 . ${ }^{\mathrm{A}} \mathrm{At}$ least one of the following: diminished vesicular breathing, wheeze, crackles, or rhonchi.

Abbreviation: $\mathrm{Cl}$, confidence interval.

\section{Discussion}

\section{Summary of key findings}

In this pooled analysis of three European studies of amoxicillin treatment for LRTI in primary care, participants who had waited longer before consulting or were prescribed a longer course of amoxicillin were more likely to initiate their course. In those who did initiate amoxicillin, older participants, or those with abnormal chest findings were more likely to implement their amoxicillin correctly on a given day. Participants were less likely to correctly implement their amoxicillin on a given day if they were prescribed a longer course. A considerable amount of variation in initiation and implementation was attributable to differences between clinicians, and the odds of initiation were higher in countries where sick certificates were required for being absent from work for $<7$ days. Course length (time from initiation to discontinuation) was longer in countries where single-handed practices were common.

\section{Strengths and limitations}

This is the first study to separately investigate the determinants of initiation, implementation, and discontinuation of antibiotic treatment and builds on previous work where we have described initiation, partial, and full adherence to antibiotics prescribed in primary care. ${ }^{3}$ In that study, we found that the odds of fully adhering to treatment was positively associated with the duration of symptoms prior to consulting, negatively associated with the duration of prescribed treatment, and varied according to antibiotic class.

This analysis used a large amount of prospective primary care data from patients in diverse settings in Europe, using similar data collection methods and with similar inclusion criteria. The determinants of nonadherence to medication can be multifaceted. ${ }^{9}$ Four of the five World Health Organizationdefined dimensions were investigated, and it was possible to assess the clustering of initiation and implementation behavior by clinician, which gave an indication of the influence of clinician attributes on patients' antibiotic treatment adherence. Characteristics of the countries from which patients were recruited were obtained and investigated, rather than estimating the differences between the countries themselves. This provided more useful information, as the goal of this study was to investigate determinants as a platform for intervening in the process, rather than simply to describe variation by country.

Our findings are consistent with previous studies of adherence to antibiotic treatment and other treatments alike. ${ }^{21-25}$

Separating out adherence into distinct processes enabled different sets of determinants to be considered. The processes are distinct, and indeed different determinants were associated with each. Had adherence been considered as a single variable, such nuances would have been missed. This approach made fuller use of the available data.

The analysis in this paper focuses on adherence to amoxicillin prescriptions for immediate use only. Although this reduces the potential number of participants (other antibiotics were prescribed and delayed prescriptions were given in the included observational studies), it allowed for the investigation of the impact of the dose, frequency, and duration without being confounded by the type of antibiotic prescribed. As amoxicillin is the most commonly prescribed and recommended antibiotic for acute respiratory infections across Europe, ${ }^{1,17}$ the results retain wide applicability. Advice regarding delayed prescriptions, while also recommended for this condition, ${ }^{26}$ are often vague (eg, here is a prescription if you get any worse), and may have been issued with the intention that the patient would never actually take antibiotic treatment. The work presented in this paper assumes that amoxicillin was prescribed for immediate use by a clinician with the intention that it would be taken as prescribed.

Our estimation of initiation, implementation, and discontinuation is based on data obtained from self-reported diaries. Although this type of measure is prone to bias, ${ }^{27,28}$ by having a daily entry, these biases are likely to be minimized. This method is also generally more feasible on larger populations, compared to more precise measures (eg, electronic monitoring) and provides more informative data than tablet counts, which can only provide an overall measure of consumption. However, questions in the diary only asked about daily the use of treatment. We have, therefore, had to assume that if 
a participant reported that they consumed amoxicillin on a given day, they consumed the correct number of doses and these doses were spread evenly throughout the day - an assumption that could have been checked with a measure, such as electronic monitoring.

To reduce any biases that may arise, from comparing adherence to medication in observational studies and trials, all analyses controlled for the study from which a patient participated.

\section{Implications}

Clinicians may be able to improve adherence to prescribed antibiotics, especially in those most likely to benefit from antibiotic treatment, by considering which patients are unlikely to start or incorrectly implement their prescription.

There are no obvious, evidence-based, reasons for variation in adherence related to the determinants we identified. There is a need to further understand the reasons for these determinants and to develop interventions to improve antibiotic use in this setting. However, the determinants that were found associated with initiation and implementation (particularly days with symptoms prior to consulting and auscultation findings) may imply that an intervention that addresses patients' perceptions about their illness might help improve adherence. Given the degree of clustering of initiation and implementation at the level of the responsible clinician, an intervention that was delivered by clinicians would seem most likely to be effective.

Given the theorized association between sub-optimal exposure to antibiotics and the development of antibiotic resistance, time from initiation to discontinuation (regardless of how correctly the medicine was implemented) does not seem to be a priority target for intervention. Although it is an element that has value in other areas (eg, medicines to be taken long term and for which there may not be a defined end date), its value for antibiotics for acute conditions is questionable.

Selection of resistance may already occur after the first dose of an antibiotic, and therefore initiation of antibiotic treatment may be the main driver of antibiotic resistance, not necessarily implementation or discontinuation. ${ }^{29}$ Nonadherence was driven by noninitiation. Different determinants were found for each adherence element.

\section{Future research}

Future work should focus on establishing whether there is a causal relationship between noninitiation, poor implementation, and clinical outcomes (eg, patient recovery, hospitalizations, re-consultations, and short- and long-term carriage of antibiotic-resistant organisms). Should a link be established, the findings reported in this paper could inform the development of an intervention that improves initiation and implementation, and in turn improves clinical outcomes for patients with acute respiratory infections in primary care.

\section{Acknowledgments}

The authors wish to acknowledge Professor Herman Goossens and Ms Jacqueline Nuttall for helping shape the manuscript. In addition, we would like to acknowledge the entire GRACE consortium for their tremendous efforts, both directly and indirectly, in shaping the work presented in this manuscript, including Tricia Worby, Alicia Borras, An De Sutter, Anna Kowalczyk, Antoni Torres, Artur Mierzecki, Bernadette Kovaks, Bo-Eric Malmvall, Carol Pascoe, Christina Lannering, Christine Lammens, Curt Brugman, Francesco Blasi, Frank Leus, Greet Ieven, Helena Hupkova, Igor Svab, Iris Hering, Jackie Swain, Janko Kersnik, Jo Coast, Jordi Almirall, Judit Holczerné, Karel Moons, Katherine Loens, Kirsi Valve, Kristien Dirven, Kristin Alise Jakobsen, Lidewij Broekhuizen, Maciek Godycki-Cwirko, Magdalena Muras, Margareta Ieven, Marieke Lemiengre, Matteu Serra, Mel Davies, Michael Moore, Niels Adriaenssens, Nuria Sanchez Romano, Paolo Tarsia, Pascale Bruno, Patricia Fernez, Peter Edwards, Peter Zuithoff, Pia Touboul, Pim de Jong, Richard Smith, Robert Veen, Saskia van Vugt, Sigvard Mölstad, Slawomir Chlabicz, Tom Schaberg, Zuzana Bielicka, and Zseraldina Arvai.

\section{Funding}

The GRACE consortium's research was funded by the European Community's Sixth Framework Programme (grant agreement 518226). Work in the UK was also supported by the National Institute for Health Research, in Barcelona by 2009 SGR 911 Ciber de Enfermedades Respiratorias (Ciberes CB06/06/0028), and in Belgium by the Research Foundation Flanders (FWO; G.0274.08N). The work reported on in this publication has been financially supported by Bond University (Australia), Research Foundation - Flanders, University of Antwerp, University of Ghent (Belgium), Chinese University of Hong Kong (People's Republic of China), University of Copenhagen (Denmark), Research Council of Health, Academy of Finland (Finland), College Azuréen des Généralistes Enseignants, Comité Départemental d'Education pour la Santé (France), Rostock University (Germany), the Netherlands Organisation for Scientific Research, AMC Amsterdam, Leiden UMC, UMC Utrecht (the Netherlands), Research Council of Norway, University of Oslo, University 
of Tromso (Norway), Medical University of Bialystok, Medical University of Lodz (Poland), National University Research Council (Romania), Osnovno zdravstvo Gorenjske (Slovenia), l'Institut d'Investigacions Biomèdiques August Pi i Sunyer (Spain), Swedish Research Council, Karolinska Institute (Sweden), Medical Research Council, Cardiff University, University of Oxford, University of Southampton (United Kingdom), Swiss National Science Foundation (Switzerland) through the European Science Foundation (ESF), in the framework of the Research Networking Programme TRACE (http://archives.esf.org/trace).

\section{Disclosure}

The authors report no conflicts of interest in this work.

\section{References}

1. Butler CC, Hood K, Verheij T, et al. Variation in antibiotic prescribing and its impact on recovery in patients with acute cough in primary care: prospective study in 13 countries. BMJ. 2009;338:b2242.

2. Currie CJ, Berni E, Jenkins-Jones S, et al. Antibiotic treatment failure in four common infections in UK primary care 1991-2012: longitudinal analysis. BMJ. 2014;349:g5493.

3. Francis NA, Gillespie D, Nuttall J, et al. Antibiotics for acute cough: an international observational study of patient adherence in primary care. Br J Gen Pract. 2012;62(599):e429-e437.

4. Kardas P, Devine S, Golembesky A, Roberts C. A systematic review and meta-analysis of misuse of antibiotic therapies in the community. Int $J$ Antimicrob Agents. 2005;26(2):106-113.

5. Berg JS, Dischler J, Wagner DJ, Raia JJ, Palmer-Shevlin N. Medication compliance: a healthcare problem. Ann Pharmacother. 1993;27 (9 Suppl):S1-S24.

6. McDonnell PJ, Jacobs MR. Hospital admissions resulting from preventable adverse drug reactions. Ann Pharmacother. 2002;36(9): 1331-1336.

7. Sclar D, Tartaglione T, Fine M. Overview of issues related to medical compliance with implications for the outpatient management of infectious diseases. Infect Agents Dis. 1994;3(5):266-273.

8. Vrijens B, Urquhart J. Patient adherence to prescribed antimicrobial drug dosing regimens. J Antimicrob Chemother. 2005;55(5):616-627.

9. Sabaté E. Adherence to Long-Term Therapies: Evidence for Action: World Health Organization, 2003.

10. Butler CC, Simpson SA, Dunstan F, et al. Effectiveness of multifaceted educational programme to reduce antibiotic dispensing in primary care: practice based randomised controlled trial. BMJ. 2012;344:d8173.

11. Little P, Stuart B, Francis N, et al. Effects of internet-based training on antibiotic prescribing rates for acute respiratory-tract infections: a multinational, cluster, randomised, factorial, controlled trial. Lancet. 2013; 382(9899):1175-1182.

12. Osterberg L, Blaschke T. Adherence to medication. N Engl J Med. 2005; 353(5):487-497.
13. Vrijens B, De Geest S, Hughes DA, et al. A new taxonomy for describing and defining adherence to medications. Br J Clin Pharmacol. 2012; 73(5):691-705.

14. GRACE website. Secondary GRACE website. Available from: http:// www.grace-lrti.org/portal/en-gb/. Accessed August 12, 2016.

15. van Vugt SF, Broekhuizen BD, Lammens C, et al. Use of serum C reactive protein and procalcitonin concentrations in addition to symptoms and signs to predict pneumonia in patients presenting to primary care with acute cough: diagnostic study. BMJ. 2013;346:f2450.

16. Little P, Stuart B, Moore M, et al. Amoxicillin for acute lower-respiratorytract infection in primary care when pneumonia is not suspected: a 12-country, randomised, placebo-controlled trial. Lancet Infect Dis. 2013;13(2):123-129.

17. Wood J, Butler CC, Hood K, et al. Antibiotic prescribing for adults with acute cough/lower respiratory tract infection: congruence with guidelines. Eur Respir J. 2011;38(1):112-118.

18. Cox DR. Regression models and life-tables. $J R$ Stat Soc Series $B$ (Methodological). 1972;34(2):187-220.

19. IBM SPSS Statistics for Windows [program]. 20.0 version. Armonk, NY: IBM Corp, 2011

20. Stata Statistical Software [program]. 13 version. College Station, TX: StataCorp LP, 2013.

21. Cockburn J, Gibberd RW, Reid AL, Sanson-Fisher RW. Determinants of non-compliance with short term antibiotic regimens. $\mathrm{Br}$ Med $J$ (Clin Res Ed). 1987;295(6602):814-818.

22. DiMatteo MR, Haskard KB, Williams SL. Health beliefs, disease severity, and patient adherence: a meta-analysis. Med Care. 2007;45(6): 521-528.

23. Llor C, Sierra N, Hernandez S, et al. The higher the number of daily doses of antibiotic treatment in lower respiratory tract infection the worse the compliance. J Antimicrob Chemother. 2009;63(2):396-399.

24. Pechere JC, Hughes D, Kardas P, Cornaglia G. Non-compliance with antibiotic therapy for acute community infections: a global survey. Int J Antimicrob Agents. 2007;29(3):245-253.

25. Vermeire E, Hearnshaw H, Van Royen P, Denekens J. Patient adherence to treatment: three decades of research. A comprehensive review. J Clin Pharm Ther. 2001;26(5):331-342.

26. Francis NA, Gillespie D, Nuttall J, et al. Delayed antibiotic prescribing and associated antibiotic consumption in adults with acute cough. Br J Gen Pract. 2012;62(602):e639-e646.

27. Aikens JE, Nease DE Jr, Nau DP, Klinkman MS, Schwenk TL. Adherence to maintenance-phase antidepressant medication as a function of patient beliefs about medication. Ann Fam Med. 2005;3(1):23-30.

28. Lu M, Safren SA, Skolnik PR, et al. Optimal recall period and response task for self-reported HIV medication adherence. AIDS Behav. 2008; 12(1):86-94.

29. Malhotra-Kumar S, Lammens C, Coenen S, Van Herck K, Goossens H. Effect of azithromycin and clarithromycin therapy on pharyngeal carriage of macrolide-resistant streptococci in healthy volunteers: a randomised, double-blind, placebo-controlled study. Lancet. 2007;369(9560): 482-490.

30. European Centre for Disease Prevention and Control. Antimicrobial consumption interactive database (ESAC-Net). Available from: http://ecdc. europa.eu/en/healthtopics/antimicrobial_resistance/esac-net-database/ Pages/overview-country-consumption.aspx. Accessed September 2, 2016.

Patient Preference and Adherence

\section{Publish your work in this journal}

Patient Preference and Adherence is an international, peer-reviewed, open access journal that focuses on the growing importance of patient preference and adherence throughout the therapeutic continuum. Patient satisfaction, acceptability, quality of life, compliance, persistence and their role in developing new therapeutic modalities and compounds to optimize

clinical outcomes for existing disease states are major areas of interest for the journal. This journal has been accepted for indexing on PubMed Central. The manuscript management system is completely online and includes a very quick and fair peer-review system, which is all easy to use. Visit http://www. dovepress.com/testimonials.php to read real quotes from published authors. 